\title{
Locomotive operation mode - the basis for developing the requirements for the energy storage device on railway transport
}

\author{
Andrey Shatokhin ${ }^{1, *}$, and Alexandr Galkin ${ }^{2}$ \\ ${ }^{1}$ Omsk State Transport University, Karl Marx Ave., 35, Omsk, 644046, Russia \\ ${ }^{2}$ Ural State University of Railway Transport, Kolmogorova Street, 66, Yekaterinburg, 620034, Russia
}

\begin{abstract}
Increasing the efficiency of cargo transportation by rail is not only one of the main directions of the company JSC "Russian Railways" but also one of the main tasks of our country in order to achieve sustainable economic growth. Electric rolling stock is the largest consumer of electric energy in the company, that's why its effective and failure-free operation is the way to solve the set tasks. The paper deals with studies related to the operation modes of a freight electric rolling stock of direct current for the purpose of determining the requirements for electric energy storage device, since it is the electric rolling stock that determines the daily schedule of electric load. The order of the analysis of experimental trips of freight electric locomotives of a direct current on the basis of cartridges of recorders of traffic parameters installed on the locomotive is determined. On the basis of the analysis of conducted trips, the main requirements for the energy storage device were obtained with a single running of electric DC rolling stock, namely the average duration of the operation modes of the electric locomotive, the maximum, minimum, and average values of voltage and current, the average value of the electric energy returned to the contact network, time of charge/discharge, and the useful energy intensity of the electric energy storage device. The studies were carried out with the support of the Russian Foundation for Basic Research for the project № 17-20-01148 ofi_m_RZD/17.
\end{abstract}

\section{Introduction}

At present, the use of operating domain technologies on railway transport has significantly increased the efficiency of cargo transportation in our country. It became common to see heavy and long trains with mass of 6-12 thousand tons [1]. However, in view of the fact that the traction energy system (TES) was implemented according to the projects of the 1960s-1980s, the handling of these masses of trains often causes difficulties. The JSC "RZD" solves this problem by carrying out various measures to strengthen the TES [2]. The author's work is aimed at finding ways to improve the TES of direct current by using innovative devices - electrical energy storage devices that will allow the company to move to environmentally friendly and resource-saving energy.

\footnotetext{
*Corresponding author: Shatohin_ap@mail.ru
} 


\section{Object and methods of research}

As is known, operation modes of electric rolling stock determine the schedule of electric load of traction substations and modes of operation of the traction energy system as a whole.

The existing problems with the handling of the electric rolling stock of increased mass and length are associated with a decrease in the voltage on the current collector of freight locomotives and the overload of power equipment of traction substations and a traction network. Determination of the traction load of ERS for trains of various masses is carried out when making traction calculations. The rules of traction calculations [3] prescribe to determine the characteristics of ERS of direct current for the voltage at the current collector when the traction mode is $3000 \mathrm{~V}$, and for the regenerative mode - $3300 \mathrm{~V}$. The above assumption allows determining the load condition of ERS, but does not reflect the picture of the change in the actual voltage on the current collector of ERS.

The software tools used for electrical calculations in the Russian Railways holding company do not allow this, too. In this regard, the use of the results of traction calculations is only possible for determination of the loading regimes of ERS. This circumstance makes it necessary to obtain experimental values of load and voltage for heavy and long trains, since, firstly, it allows analyzing the change in both the traction load and the voltage level at the current collector of ERS, and, secondly, it allows determining the limiting operation modes of energy storage device in TES.

These systems are widely used abroad in lighter transport (bus, trolleybus, etc.), which provides an incentive for the development of such systems for heavier transport [4-6]. As shown by the results of the efficiency assessment of the location of the energy storage device, the most efficient is the location of the energy storage device on the board of ERS, for example, as shown in $[7,8]$. In the traction energy system, the most effective location from the technical point of view is the linear installation - the section pillar of the contact network or the point of parallel connection [9-14].

\section{Results}

The following is the procedure for analyzing experimental trips in order to study the electric regimes for the heavy and long train traffic.

At the initial stage, it is necessary to identify heavy and long trains with the necessary locomotive series from the daily train sheet in a certain section of operation, for which it is necessary to use the "URAL VNIIZhT" Train Sheet hardware-software complex. As an example, Fig. 1. shows the train sheet for an electric locomotive № XX of the 2ES10 series with the mass of 5,977 tons within the boundaries of the section E-Sh.

The most important factor affecting the operation modes of an electric locomotive is the path profiles of the operation section (in the example considered, the path profile is of the IV type [15]).

Then, based on the decoding of the cartridges using the parameter recorder, the curves of current and voltage on the current collector of the locomotive 2ES10 were obtained (Fig. 2). 


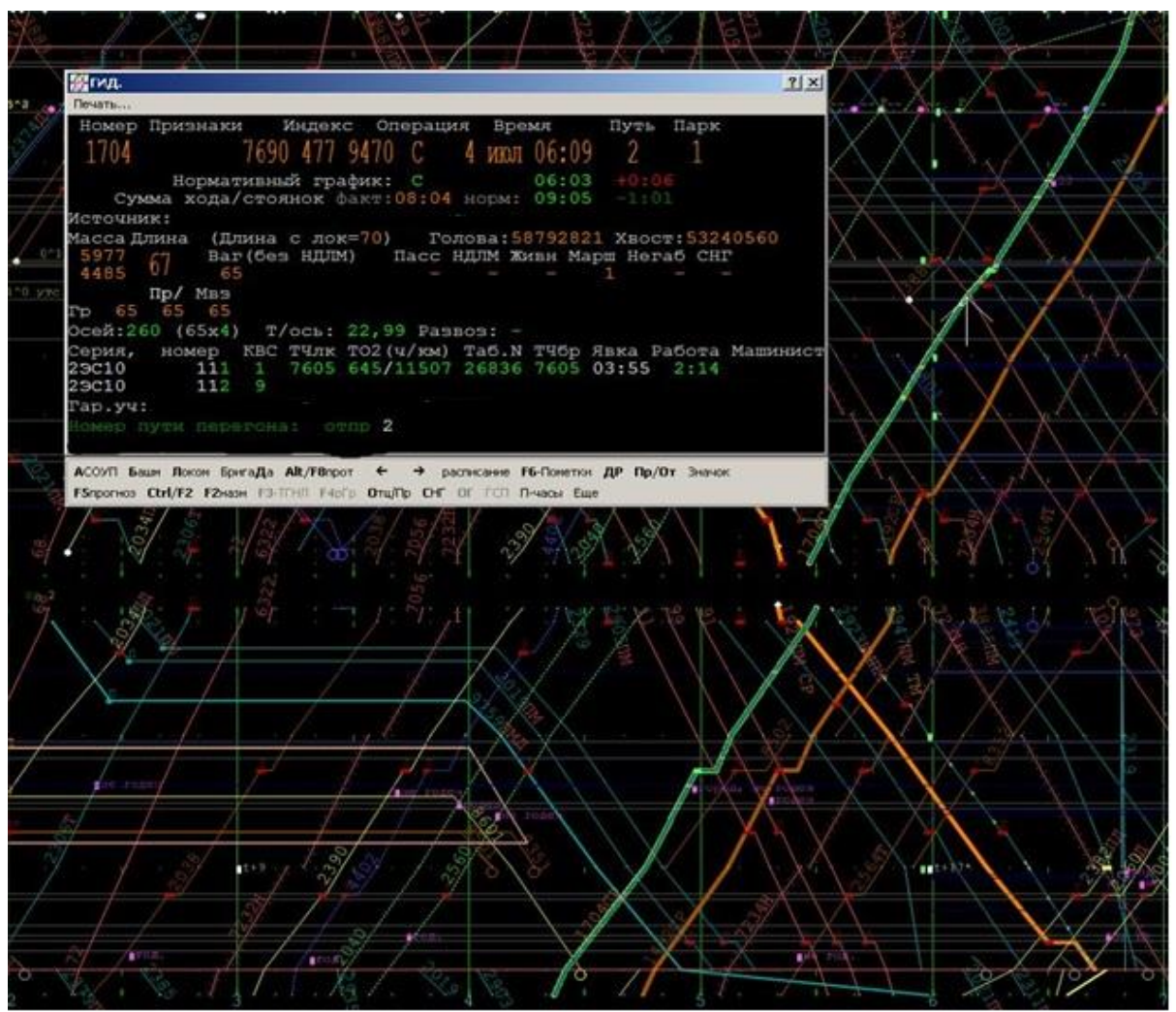

Fig. 1. Train sheet for an electric locomotive during an experimental trip on the section E-Sh.

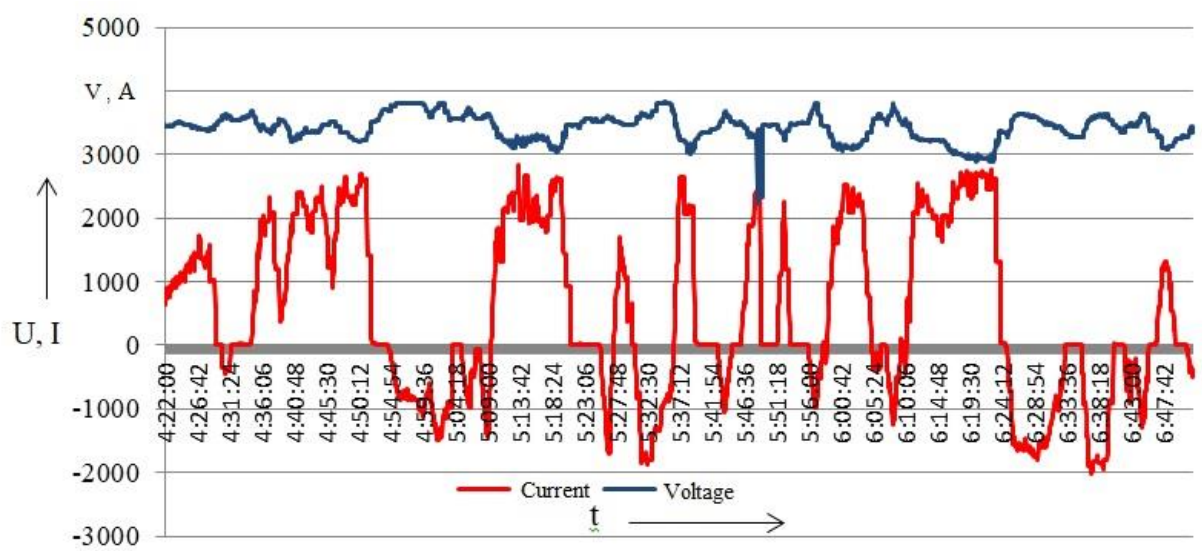

Fig. 2. Curves of load and voltage on the current collector of the electric locomotive 2ES10 №XX on the section $\mathrm{E}-\mathrm{Sh}$.

The histogram of distribution of the observed voltage values on the current collector of 2ES10 № XX according to the results of the trip under consideration is shown in Fig. 3. Voltage distribution on the current collector is obtained for TES with controlled reactors on the current collector, stabilizing the voltage level on the bus bars of $3.3 \mathrm{kV}$. 


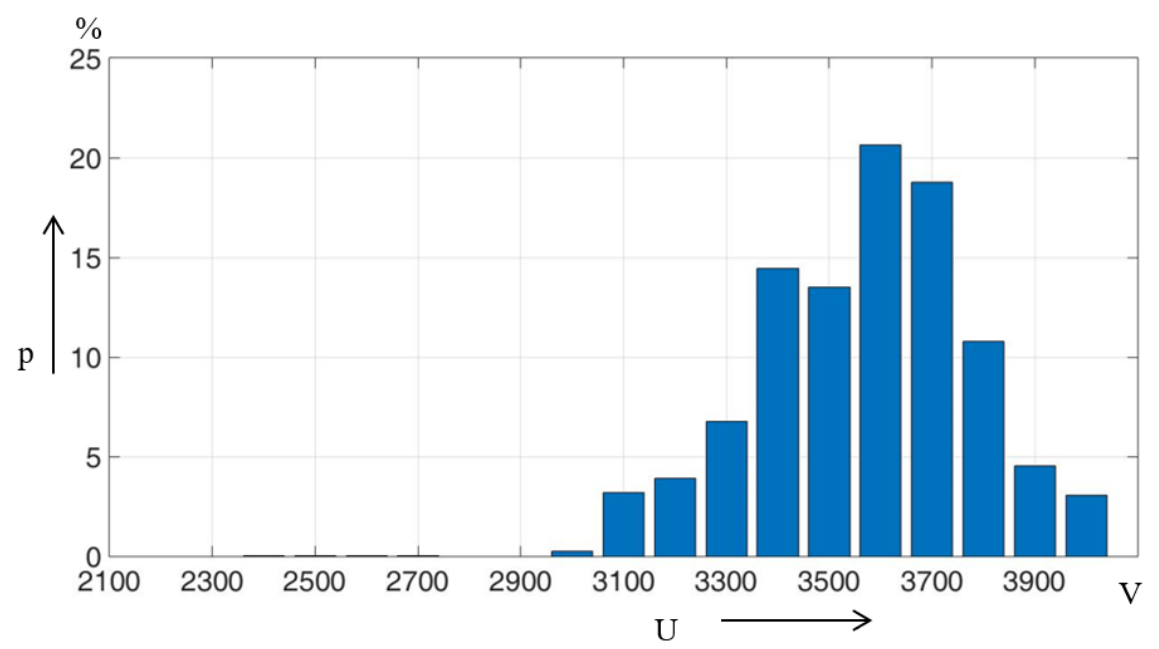

Fig. 3. The histogram of the voltage distribution on the current collector of the electric locomotive 2ES10 № XX on the section E - Sh.

In conditions of stabilizing the voltage on the bus bars of the current collector at the level of $3600-3650 \mathrm{~V}$, the range of $3550-3650 \mathrm{~V}$ is the most observed range of voltage values on the current collector of the locomotive in question. These values are observed for $20 \%$ of the observed travel time. In the regenerative braking mode, as will be shown below, the voltage on the current collector varies over a wide range. For the operation of energy storage device, first of all, for the charge mode, it is necessary to determine the observation frequency of voltage above the open circuit operation voltage level of the current collector. For the trip under consideration, the voltage above the $3650 \mathrm{~V}$ level is observed in $35 \%$ of the time, which determines the potential charging time of the energy storage device. In the third range of values - from 2900 to $3550 \mathrm{~V}$ - the voltage on the current collector of 2ES10 is observed during $45 \%$ of the travel time. The histogram of distribution of the observed currents in different operating modes of 2ES10 is presented in Fig. 4. For the trip under consideration, the regenerative braking mode is recorded with currents reaching a level of $1500 \mathrm{~A}$. The time during which the recovery currents are recorded was about $25 \%$ of the travel time.

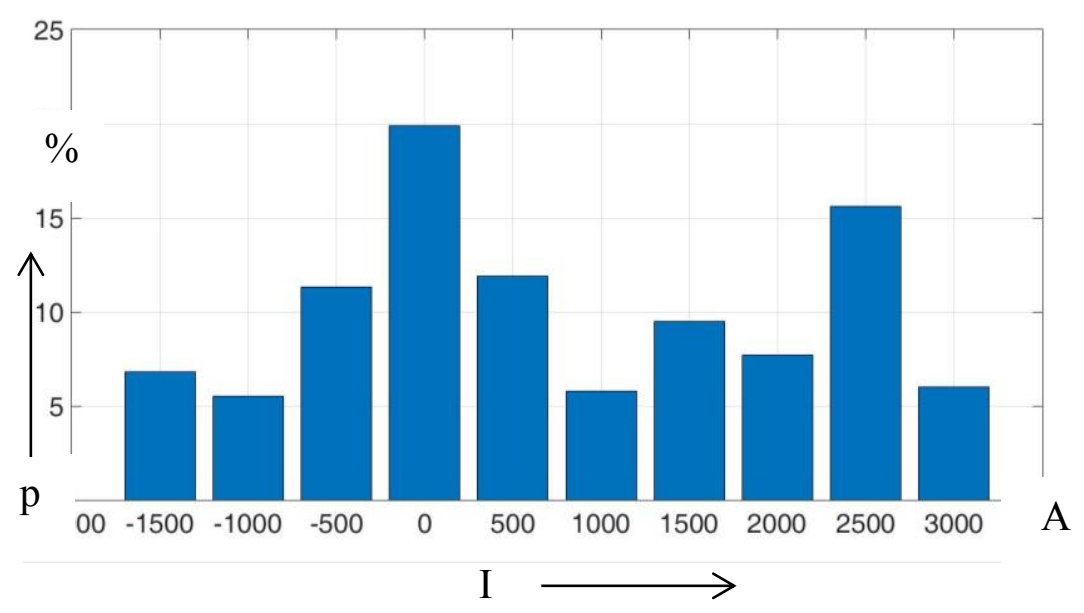

Fig. 4. The histogram of current distribution of the electric locomotive 2ES10 № XX on the section E - Sh. 
The observed values of voltage and current when handling a heavy or long train should be considered in various modes of operation of ERS in order to obtain the characteristic of the traction regime and regenerative braking. For this purpose, it seems expedient to sequentially identify alternating modes of operation of ERS and to consider in more detail the regime of recovery.

There are three modes of operation of the locomotive in this trip (traction, runout or operation waiting, and regenerative braking). Taking into account the constant regime changes during locomotive operation on a trip, it is necessary to allocate each case of application of a particular operation mode and to consider in more detail such parameters of the regime as duration, energy consumption, minimum and maximum values of current and voltage.

Let's consider the operating characteristics of the electric locomotive 2ES10 № XX on the section E-Sh in the regenerative mode (table 1).

Table 1. Characteristics of regenerative braking during experimental trip by electric locomotive 2ES10 № XX.

\begin{tabular}{|c|c|c|c|c|c|c|}
\hline \multicolumn{7}{|c|}{ Regenerative braking mode } \\
\hline $\mathrm{N}$ of case & $\mathrm{W}, \mathrm{kW} \cdot \mathrm{h}$ & $\mathrm{I}_{\min }, \mathrm{A}$ & $\mathrm{I}_{\max }, \mathrm{A}$ & $\mathrm{U}_{\max }, \mathrm{V}$ & $\mathrm{U}_{\min }, \mathrm{V}$ & $\mathrm{t}, \mathrm{sec}$ \\
\hline 1 & -28 & -77 & -436 & 3640 & 3540 & 81 \\
\hline 2 & -515 & -112 & -1488 & 3820 & 3540 & 561 \\
\hline 3 & -160 & -56 & -1448 & 3740 & 3552 & 258 \\
\hline 4 & -109 & -19 & -1706 & 3620 & 3520 & 117 \\
\hline 5 & -421 & -139 & -1866 & 3840 & 3500 & 339 \\
\hline 6 & -72 & -56 & -1056 & 3700 & 3428 & 120 \\
\hline 7 & -72 & -96 & -984 & 3800 & 3460 & 126 \\
\hline 8 & -2 & -24 & -288 & 3440 & 3440 & 18 \\
\hline 9 & -24 & -104 & -400 & 3640 & 3480 & 72 \\
\hline 10 & -88 & -17 & -1252 & 3800 & 3460 & 129 \\
\hline 11 & -4 & -16 & -457 & 3560 & 3480 & 18 \\
\hline 12 & -658 & -8 & -1808 & 3640 & 3300 & 528 \\
\hline 13 & -419 & -48 & -2008 & 3640 & 3280 & 282 \\
\hline 14 & -132 & -40 & -1289 & 3640 & 3360 & 216 \\
\hline 15 & -16 & -56 & -504 & 3440 & 3280 & 54 \\
\hline Average & -181 & -58 & -1133 & 3664 & 3441 & 195 \\
\hline
\end{tabular}

The data processing for the regenerative braking mode revealed 15 cases of using the regenerative braking by the locomotive 2ES10. The average amount of electric energy returned to the contact network for the observed cases of locomotives in the regenerative braking mode was $181 \mathrm{~kW} \mathrm{~h}$, the average duration of one case was $195 \mathrm{~s}$. The average value of the maximum recovery current for the cases under consideration was $1133 \mathrm{~A}$, the average value of the minimum current was $58 \mathrm{~A}$, and the corresponding values of the voltage level at the current collector were $3664 \mathrm{~V}$ and $3441 \mathrm{~V}$.

Based on the results of processing trip data for different operation modes of 2ES10 № XX, it is necessary to present frequency histograms for the observed minimum and maximum values of currents and voltages on the current collector of the locomotive in the cases. As an example, the frequency histograms are shown in the regenerative mode (Figures $5,6)$. 


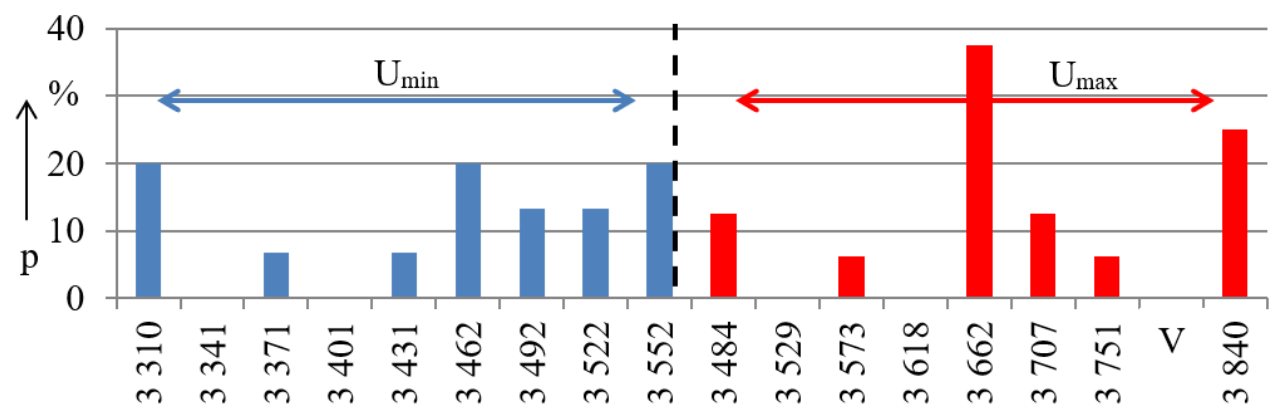

Fig. 5. Frequency histogram of the appearance of the minimum and maximum voltage in the regenerative mode on the current collector of the electric locomotive $2 \mathrm{ES} 10$ №. XX on the section E Sh.

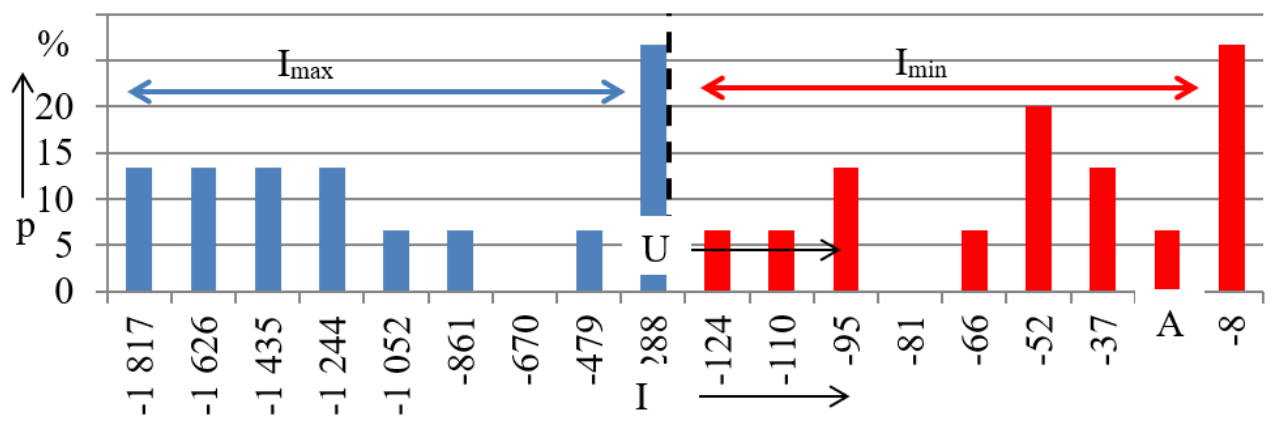

Fig. 6. Frequency histogram of the appearance of the minimum and maximum current in the regenerative mode on the current collector of the electric locomotive 2ES10 №. XX on the section E $-\mathrm{Sh}$.

To characterize the charging mode of the energy storage device, it is necessary to evaluate the maximum voltage levels in the contact network when the ERS is in the regenerative braking mode. When using regenerative braking by the electric locomotive 2ES10, the voltage on the current collector varies over a wide range of 3310-3840 V, while the most likely level of voltage on the current collector in cases of using regeneration is about 3660 V. The current of the electric locomotive 2ES10 № XX in the regenerative mode is about $1820 \mathrm{~A}$ in $13 \%$ of the observed travel time, and the most observed value of the recovery current is about $290 \mathrm{~A}(27 \%$ of the observed time).

\section{Conclusions}

The results of processing the data of experimental trips of heavy and long trains allow us to draw the following conclusions:

1) the averaged values of the duration of the traction mode for the 2ES6 series are $545 \mathrm{~s}$, for the regenerative mode is $109 \mathrm{~s}$. For the $2 \mathrm{ES} 10$ series, the average values of the duration of the traction mode are $335 \mathrm{~s}$, for the regenerative mode is $216 \mathrm{~s}$;

2) the averaged values of the electric energy consumption for each case in the traction mode for the 2ES6 series are $534 \mathrm{~kW} \mathrm{~h}$, in the regenerative mode the return volume is 107 $\mathrm{kW} \mathrm{h}$. For the $2 \mathrm{ES} 10$ series, the corresponding values are $416 \mathrm{~kW} \mathrm{~h}$ and $161 \mathrm{~kW} \mathrm{~h}$, respectively; 
3 ) the maximum instantaneous values of current and voltage in the regenerative mode for the 2ES6 series are - $2121 \mathrm{~A}$, for the series 2ES10 - $2088 \mathrm{~A}$. The maximum power returned to the contact network in the regenerative mode for the 2ES6 series is $7.2 \mathrm{MW}$, for the 2ES10 series - 7.1 MW;

4) the averaged values of the maximum current and voltage levels for the cases of using regeneration for locomotives of the 2ES6 series are $891 \mathrm{~A}$ and $3505 \mathrm{~V}$, respectively, for the 2ES10 series - $890 \mathrm{~A}$ and $3670 \mathrm{~V}$;

5) the average values of the regenerative energy returned to the contact network for all types of path profiles vary in the range of $73-126 \mathrm{~kW} \mathrm{~h}$, while for the $2 \mathrm{ES} 6$ series in $75 \%$ of cases, the regenerative volume is up to $90 \mathrm{~kW} \mathrm{~h}$, for the $2 \mathrm{ES} 10$ series in $60 \%$ of cases - up to $100 \mathrm{~kW} \mathrm{~h}$;

6) more than $85 \%$ of the observed cases, the recovery time for the 2ES6 series is up to $200 \mathrm{~s}$, for the $2 \mathrm{ES} 10$ series in more than $70 \%$ of the cases, the recovery time is up to $400 \mathrm{~s}$;

7) the highest level of the average values of the maximum current for each application of regenerative braking is achieved on sections with the IV type of the profile - up to $1030 \mathrm{~A}$. The average of the observed maximum values of the voltages on the current collector in the regenerative braking mode on sections with the IV type of profile is $3600 \mathrm{~V}$;

8 ) with regard to the single running of heavy and long trains, the following requirements for the energy parameters of the energy storage device should be determined: charge/discharge time $-550 / 220 \mathrm{~s}$, useful energy intensity $-530 / 160 \mathrm{~kW} \mathrm{~h}$.

\section{References}

1. T.N. Kalikina, Yu. A. Davydov, A.K. Plyaskin, M. Yu. Keino, Innovative transport 2(20), $72-74$ (2016)

2. Infrastructure of railway transport on the sections of circulation of freight trains of increased weight and length. Technical requirements: SRT RZD 1.07.002-2010 (JSC "Russian Railways", Moscow, 2010)

3. Rules of traction calculations, Approved by the order of JSC “RZD” (2016)

4. Kiepe Electric liefert ersten 24-Meter-Elektro-Bus nach Linz, https://www.ebinfo.eu/aktuell/aus-den-unternehmen/12-10-2017-kiepe-electric-liefert-ersten-24meter-elektro-bus-nach-linz/559221/

5. ÖBB-Hybridlok mit Brennstoffzelle: Versuchslokomotive mit alternativem Antriebskonzept getestet, https://www.eb-info.eu/aktuell/forschung-undentwicklung/11-10-2017-oebb-hybridlok-mit-brennstoffzelle-versuchslokomotive-mitalternativem-antriebskonzept-getestet/

6. Bundesverband eMobilität fordert Elektrobus-Initiative, https://www.ebinfo.eu/aktuell/politik/06-10-2017-bundesverband-emobilitaet-fordert-elektrobussinitiative/

7. H.T. Yap, N. Schofield, C.M. Bingham, Power Electronics, Machines and Drives, Second International Conference 498 (2004)

8. Traction Energy Storage System with $\mathrm{SCiB}^{\mathrm{TM}}$ Item Rating,Function For DC Railway Power Supply Systems, http://www.toshiba.co.jp/sis/railwaysystem/en/products/ catalog/pdf/c10TESS.pdf

9. V.L. Nezevak, M.M. Nikiforov, V.T. Cheremisin, Science and Transport, Modernization of railway transport 2(6), 14-18 (2013)

10. V.T. Cheremisin, V.L. Nezevak, Bulletin of the results of scientific research, SaintPetersburg State Transport University 1(14), 307-314 (2015) 
11. V.T. Cheremisin, V.L. Nezevak, A.P. Shatohin, International Journal of Advanced Railway (The Korean Society for Urban Railway) 1(2), 53-56 (2013)

12. V.L. Nezevak, A.P. Shatokhin, V.T. Cheremisin, Bulletin of the Tomsk Polytechnic University 10, 54-64 (2015)

13. A.P. Shatokhin, Materials of the 2nd All-Russian Scientific and Practical Conference with international participation, Omsk State Transport University, 162-168 (2014)

14. V.L. Nezevak, A.P. Shatokhin, Proceedings of the International Scientific and Practical Conference, Rostov State Transport University, 169-171 (2015)

15. A.M. Baranov, V.E. Kozlov, E. D. Feldman, Proceedings of the All-Union Scientific, Research Institute of Railway Transport 280, 196 (1964) 